\title{
Prevalence of Elevated Blood Pressure and Association with Obesity in Egyptian School Adolescents
}

\author{
Mostafa A. Abolfotouh, ${ }^{1}$ Sunny A. Sallam, ${ }^{2}$ Mohammed S. Mohammed, ${ }^{2}$ \\ Amany A. Loutfy, ${ }^{2}$ and Ali A. Hasab ${ }^{2}$ \\ ${ }^{1}$ King Abdullah International Medical Research Center (KAIMRC), King Saud bin Abdulaziz University for \\ Health Sciences (KSAU-HS), P.O. Box 22490, Riyadh 11426, Saudi Arabia \\ ${ }^{2}$ Department of Epidemiology, High Institute of Public Health, Alexandria University, Alexandria 21526, Egypt
}

Correspondence should be addressed to Mostafa A. Abolfotouh, mabolfotouh@gmail.com

Received 19 December 2010; Accepted 17 January 2011

Academic Editor: Kazuko Masuo

Copyright (C) 2011 Mostafa A. Abolfotouh et al. This is an open access article distributed under the Creative Commons Attribution License, which permits unrestricted use, distribution, and reproduction in any medium, provided the original work is properly cited.

\begin{abstract}
Aim. To investigate the relationship between high blood pressure (HBP) and obesity in Egyptian adolescents. Methods. A cross-sectional study of 1500 adolescents (11-19 years) in Alexandria, Egypt, was conducted. Resting BP was measured and measurements were categorized using the 2004 fourth report on blood pressure screening recommendations. Additional measures included height, weight, and waist and hip circumferences. Obesity was determined based on BMI, waist circumference (WC) and waist-to-hip ratio (WHR), and waist-to-height ratio (WHtR) indicators. Crude and adjusted odds ratios were used as measures of association between BP and obesity. Results. Prevalence rates of prehypertension and hypertension were $5.7 \%$ and $4.0 \%$, respectively. Obesity was seen in $34.6 \%, 16.1 \%, 4.5 \%$, and $16.7 \%$ according to BMI, WHR, WC, and WHtR, respectively. Adjusting for confounders, HBP was significantly associated with overall obesity based on BMI $(\mathrm{OR}=2.18,95 \%, \mathrm{CI}=1.38-3.44)$ and central obesity based on WC $(\mathrm{OR}=3.14,95 \%, \mathrm{CI}=1.67-5.94)$. Conclusion. Both overall obesity and central obesity were significant predictors of HBP in Egyptian adolescents.
\end{abstract}

\section{Introduction}

The importance of hypertension in the pediatric population has not been as well appreciated as in adults. Children with elevated blood pressure (BP) can develop target organ damage [1], and they are also at increased risk of cardiovascular disease in adulthood [2]. Consequently, detection and management of elevated BP at an early age may be an important means for limiting the disease burden due to hypertension [3].

The prevalence of HBP among children in several recently conducted studies in Western countries ranged from 7 to $19 \%$ [4-6]. However, few studies have been conducted in children in developing countries. A study of blood pressure levels among primary school students in Kuwait found that the overall prevalence of hypertension was 5.1\% [7], 3.6\% among school children in Jordan [8], and $4.30 \%$ among preparatory school children in Alexandria [9].
The prevalence of childhood obesity has increased markedly over the last 2 decades [10-14]. This increase is associated with an increase in hypertension rates which could lead to atherosclerotic disease in adulthood $[15,16]$. Primary hypertension in children has become increasingly common in association with other cardiovascular risk factors that include being overweight, insulin resistance, and dyslipidemia [16].

Many studies have shown that blood pressure is associated with being overweight in children and adolescents of Western countries $[4-6,17]$. However, few data are available in non-Western countries and in non-Caucasian populations [18-20]. Previous studies [21-23] reported ethnic variation in the relationship of overweight/obesity and change in blood pressure, and this ethnic variations could be either genetic or environmental or both. Thus, the aims of the present study were (i) to estimate the prevalence of HBP, and (ii) to investigate the relationship between BP and different body 
composition measures in Egyptian school adolescents in Alexandria city, Egypt. To our knowledge this study is the first to investigate this relationship in Egyptian adolescents.

\section{Materials and Methods}

2.1. Study Design. A cross-sectional study was conducted with a total of 1500 school adolescents from different preparatory and secondary schools in Alexandria city, Egypt.

2.2. Study Population and Sampling Technique. The minimum required sample was calculated by using Epi-Info software program, on assumption that the prevalence of hypertension among school children is $4.30 \%$ [9]. The calculated sample at $95 \%$ confidence level was found to be 1475 students. Thus, a total sample of 1500 school adolescents enrolled in preparatory and secondary schools was considered, to compensate for drop out.

Three educational zones were selected randomly of the seven zones in Alexandria. Of each zone, four governmental schools were allocated randomly to represent preparatory and secondary education for both sexes. Thus, a total number of 12 schools were chosen. Of each selected school, 3 classrooms were selected at random to represent the 3 educational grades.

\subsection{Techniques}

2.3.1. Assessment of Body Composition. Anthropometric measures were taken in school clinics by a trained team. All measurements were performed twice. Height was measured without shoes to the nearest $0.1 \mathrm{~cm}$ using a portable stadiometer. Weight was measured in light clothing to the nearest $0.1 \mathrm{~kg}$ using a digital Heine portable scale. WC was measured at the narrowest area above the umbilicus or mid way between the coastal margin and the iliac crest, in a horizontal plane at the end of normal expiration, with the tape measure snugly fitted $[24,25]$. Hip circumference was measured at the maximal gluteal protrusion or at the most prominent area of the buttocks at the level of symphysis pubis in a horizontal plane. The tape measure was held snugly against the body but without compression [24, 25].

BMI was calculated as the ratio of weight $(\mathrm{kg})$ to height (m) squared $\left(\mathrm{kg} / \mathrm{m}^{2}\right)$. The 5th, 85th, and 95th percentiles were calculated according to the international statistics standards [26]. Adolescents were classified based on these percentiles as follows: $<5$ th underweight, 5 th -85 th normal weight, 85th-95th overweight, and 95th + considered obese [27].

The 90th percentile values for $W C$ for gender and age generated in the National Health and Nutrition Examination Survey (NHANES III) were used as cut-off values to identify adolescents with abdominal obesity [24, 28].

WHR was calculated by dividing waist by hip circumference, and abdominal obesity was diagnosed when the WHR was $>0.80$ in girls and 0.95 in boys [29]. WHtR was calculated as the ratio of waist $(\mathrm{cm})$ and height $(\mathrm{cm})$. A WHtR cut-off of
0.5 is used to define abdominal obesity for both 6-19-yearold boys and girls [24].

2.3.2. Blood Pressure Measurement. BP was measured using the standardized mercury sphygmomanometer with manually inflated cuff of suitable size and a stethoscope. It was measured on the right arm after the child was sitting quietly for 5 minutes to relieve anxiety, and seated with his or her back supported, feet on the floor, right arm supported, and cubital fossa at heart level left arm. Two readings were obtained at a 1-min. interval, and the average was recorded. The blood pressure was measured two times with zero device. SBP was determined by the onset of the "tapping" korotkoff sounds (K1) and the fifth korotkoff sound (K5), or the disappearance of korotkoff sounds, as the definition of DBP.

The mean values of blood pressure were measured and corrected for age and sex in the form of centile bands and compared with US National Childhood Blood Pressure standards [30]. The blood pressure percentiles were determined accordingly.

When the BP was greater than the 90th percentile for age, gender, and height, measuring $\mathrm{BP}$ was repeated twice at the same visit, and average SBP and DBP were used. If BP was greater than the 95th percentile, BP was staged to stage I (95th percentile to the 99th percentile plus $5 \mathrm{mmHg}$ ) and stage 2 ( $>99$ th percentile plus $5 \mathrm{mmHg}$ ) [30]. Adolescents aged 18 and 19 years in the study were considered as adults and were classified as follows: hypertension is defined as average SBP $>120$ and DBP $>80 \mathrm{mmHg}$. Prehypertension is defined as average SBP $120-139$ or DBP $80-89 \mathrm{mmHg}$. Stage I hypertension is defined as average SBP $140-159$ or DBP 90-99 $\mathrm{mmHg}$. Stage II hypertension is defined as average SBP greater than or equal 160 or DBP greater than or equal $100 \mathrm{mmHg}[31]$.

2.3.3. Interview Questionnaire. In order to adjust for the many of the possible confounders for the association between obesity and high blood pressure among adolescents, all students of the study sample were subjected to a selfadministered questionnaire. The designed questionnaire was composed of the following.

(1) Personal history of chronic diseases, such as, hypertension, diabetes mellitus, renal diseases, and endocrine diseases, and taking antihypertensive drugs, corticosteroid, insulin, or penicillin.

(2) Family history of chronic disease, such as hypertension, obesity, and diabetes mellitus. The degree of relative divided to near and far. The near relative was considered father, mother, brother, and sister. The far relative was considered as others such as aunt, uncle, grandfather, and grandmother.

(3) Lifestyle: this includes the following: (a) Dietary habits: intake of salty and fatty diet (very high, high, moderate, and little consumption). (b) Physical activity: physically active or nonactive. (c) Smoking: regular smoker/nonsmoker. Only daily and weekly smokers were considered as regular smokers. Daily 
smokers were those who, at the time of the survey, smoked cigarettes every day. Weekly smokers were those who smoked less than once a day but at least once a week. Physically active adolescents were those who reported practicing exercise more than one hour at least 3 times per week [32].

A pilot study was carried out on 25 students in 2 schools (one preparatory and the other secondary) in Alexandria at the middle districts.

The pilot study aimed to test the validity and clarity of the structured questionnaire for the intended school adolescents, pretest the study tools in order to reveal any modifications needed, estimate the average time needed to obtain the required information, identify any possible potential difficulties in data collection, and examine the overall survey technique to be used.

2.4. Data Analysis. Statistical analysis was done with aid of the computer program SPSS (statistical package for the social sciences). Descriptive measures as arithmetic mean and standard deviation were used to describe quantitative data. Student's $t$-test was used to compare between sample means for quantitative data. Person's chi-square " $\chi^{2}$ ", Mantel- Haenszel chi-square, and chi-square for linear trend were applied to gauge the difference between categorical data. Logistic regression was used to assess the relationship between the different body composition measures and elevated BP, adjusting for age, sex, smoking behaviour, food and salt consumption, history of chronic disease, family history of hypertension, diabetes mellitus, and obesity. Statistical significance was set at $P<.05$.

2.5. Ethical Consideration. All measurements were done in private rooms in the school clinics. All collected data by the self-reported questionnaires were kept confidential. All participants had the right not to participate in the study or to withdraw from the measurements prior to its completion. The study protocol received ethical approval from the Research Committee of the High Institute of Public Health, Alexandria university, Egypt.

\section{Results and Discussion}

Table 1 shows the distribution of study sample according to the levels of blood pressure and body composition measures. The prevalence rates of prehypertension and hypertension were $5.7 \%$ and $4.0 \%$, respectively, with no sex difference $\left(\chi^{2}=5.86, \mathrm{df}=4, P=.12\right)$. Overall obesity prevalence-based on BMI measure-was 10.3\%. Overall obesity was significantly more prevalent in male than in female adolescents (11.8\% versus $8.7 \%, P=.002)$. Central obesity was prevalent in $16.1 \%, 4.5 \%$, and $16.7 \%$ based on WHR, WC, and WHtR measures, respectively. Males showed significantly higher prevalence of central obesity based on WC $\left(5.9 \%\right.$ versus $\left.3.2 \%, \chi^{2}=6.16, \mathrm{df}=1, P=.013\right)$ while female adolescents showed significantly higher prevalence of central obesity based on WHR (31.9\% versus $0.3 \%, \chi^{2}=$ 277.7, $\mathrm{df}=1, P<.001)$.

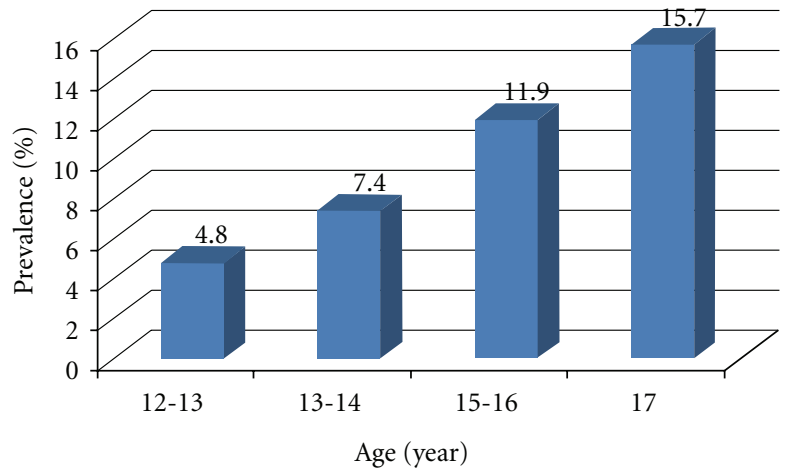

Figure 1: Prevalence of elevated blood pressure in Egyptian adolescents according to age.

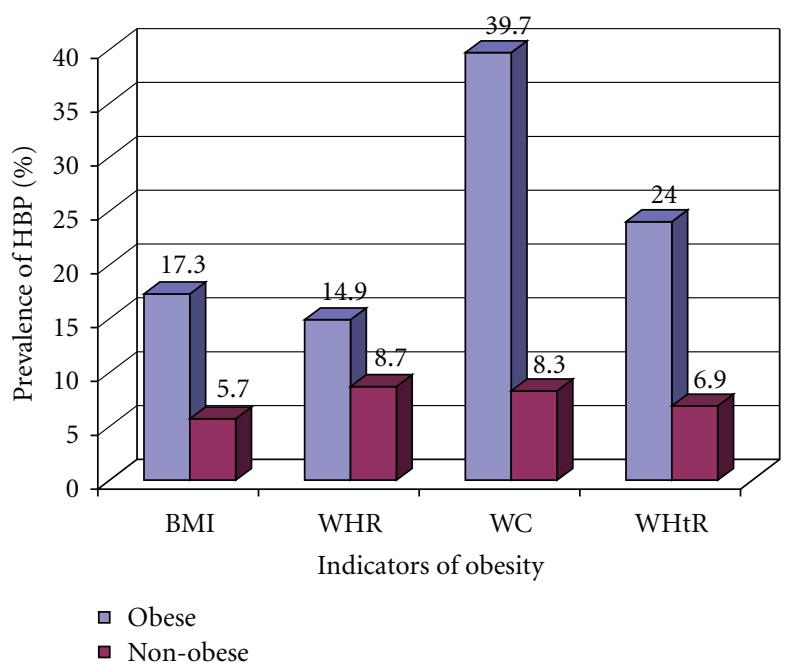

Figure 2: Prevalence of elevated blood pressure in Egyptian adolescents according to different obesity indicators.

Figure 1 shows that there was a significant gradual increase in the prevalence of elevated blood pressure with the advancement of age of the adolescents. This prevalence increased from $4.8 \%$ in adolescents aged 13 to 14 years to $15.7 \%$ in adolescents 17 years of age. $\left(\chi_{L}^{2}=18.603, P<.001\right)$.

Table 2 and Figure 2 show the association between body composition measures and high blood pressure among school adolescents. Compared with those of normal weight, obese adolescents had significantly greater odds of having high blood, whether defined by BMI $(\mathrm{OR}=3.47,95 \% \mathrm{CI}=$ 2.44-4.93), WC $(\mathrm{OR}=4.27,95 \% \mathrm{CI}=2.97-6.15)$, WHR $(\mathrm{OR}=1.83,95 \% \mathrm{CI}=1.22-2.75)$, or WHtR $(\mathrm{OR}=7.27$, $95 \% \mathrm{CI}=4.32-12.23)$. When all body composition measures were adjusted for all the potential confounders in a logistic analysis (age, history of chronic diseases, family history of hypertension, and family history of diabetes mellitus), both BMI and the WC measures were the only significant predictors of high blood pressure in school adolescents. Blood pressure was significantly high among adolescents 
TABLE 1: Distribution of the study sample of school adolescents according to patterns of blood pressure and body composition by sex.

\begin{tabular}{|c|c|c|c|c|c|c|}
\hline & \multicolumn{2}{|c|}{ Male $(n=750)$} & \multicolumn{2}{|c|}{ Female $(n=750)$} & \multicolumn{2}{|c|}{ Total (1500) } \\
\hline & No. & $\%$ & No. & $\%$ & No. & $\%$ \\
\hline \multicolumn{7}{|l|}{$\mathrm{BP}$} \\
\hline Normal BP & 667 & 89.0 & 687 & 91.6 & 1354 & 90.3 \\
\hline Prehypertension & 49 & 6.5 & 36 & 4.8 & 85 & 5.7 \\
\hline Stage I HBP & 21 & 2.8 & 22 & 2.9 & 43 & 2.8 \\
\hline Stage II HBP & 13 & 1.7 & 5 & 0.7 & 18 & 1.2 \\
\hline Prevalence@ & 83 & 10.0 & 63 & 8.4 & 146 & 9.7 \\
\hline Sex difference & \multicolumn{4}{|c|}{$\chi^{2}=5.86, \mathrm{df}=4, P=.12$} & & \\
\hline \multicolumn{7}{|l|}{ BMI percentiles } \\
\hline$<5$ th underweight & 312 & 41.6 & 291 & 38.8 & 603 & 40.2 \\
\hline 5th-85th (normal weight) & 349 & 46.5 & 394 & 52.5 & 743 & 49.5 \\
\hline 85th-95th (overweight) & 46 & 6.1 & 48 & 6.4 & 94 & 6.3 \\
\hline$\geq 95$ th (obese) & 43 & 5.7 & 17 & 2.3 & 60 & 4.0 \\
\hline Prevalence $_{\#}$ & 89 & 11.8 & 65 & 8.7 & 155 & 10.3 \\
\hline Sex difference & \multicolumn{4}{|c|}{$\chi^{2}=14.77, \mathrm{df}=3, P=.002$} & & \\
\hline \multicolumn{7}{|l|}{ WHR } \\
\hline Nonobese & 748 & 99.7 & 511 & 68.1 & 1259 & 83.9 \\
\hline Obese (Prev.) & 2 & 0.3 & 239 & 31.9 & 241 & 16.1 \\
\hline \multicolumn{7}{|c|}{$\chi^{2}=277.7, \mathrm{df}=1, P=<.001$} \\
\hline \multicolumn{7}{|l|}{ WC percentiles } \\
\hline Non obese $<90$ th & 706 & 94.1 & 726 & 96.8 & 1432 & 95.5 \\
\hline Obese $\geq 90$ th (Prev.) & 44 & 5.9 & 24 & 3.2 & 68 & 4.5 \\
\hline Sex difference & \multicolumn{4}{|c|}{$\chi^{2}=6.16, \mathrm{df}=1, P=.013$} & & \\
\hline \multicolumn{7}{|l|}{ WHtR } \\
\hline$<0.5$ & 611 & 81.5 & 639 & 85.2 & 1250 & 83.3 \\
\hline$\geq 0.5$ (Prev.) & 139 & 18.5 & 111 & 14.8 & 250 & 16.7 \\
\hline Sex difference & \multicolumn{4}{|c|}{$\chi^{2}=3.76, \mathrm{df}=1, P=.052$} & & \\
\hline
\end{tabular}

${ }^{\circledR}$ Prevalence of elevated BP includes prehypertensive adolescents.

${ }^{\#}$ Prevalence of overweight and obesity.

who are obese by BMI $(\mathrm{OR}=2.18,95 \% \mathrm{CI}=1.38-3.44)$ and those who are obese by WC $(\mathrm{OR}=3.14,95 \% \mathrm{CI}=1.67-5.94)$.

Table 3 shows that high blood pressure was significantly more prevalent among school adolescents with positive history of chronic diseases $(\mathrm{OR}=2.46,95 \% \mathrm{CI}=1.46-4.15)$, those with positive family history of high blood pressure $(\mathrm{OR}=1.61,95 \% \mathrm{CI}=1.14-2.27)$, and those with positive family history of diabetes mellitus $(\mathrm{OR}=1.53,95 \% \mathrm{CI}=$ 1.08-2.15). However, there was no significant association between high blood pressure and family history of obesity. With regard to the lifestyles and health-related behavior of adolescents, high blood pressure showed no significant association with any of these behaviours.

In the present study, prevalence rates of prehypertension and hypertension were $5.7 \%$ and $4.0 \%$, respectively. These figures were lower than those among Iranian adolescent girls (13.9\%, and 19.4\%) [33], and figures among US adolescents (15.7\%, and 3.2\%) [34]. They were also similar to prevalences in urban South Africa [35]. There was a gradual and progressive significant increase in the prevalence of elevated blood pressure from $4.8 \%$ in young adolescents aged 13 to 14 years up to $15.7 \%$ in those aged 17 years. However, comparison of the prevalence of elevated BP with other studies is limited due to differences in the procedures used for BP measurement across studies.

Many studies have documented an association between BP and body weight. Few population-based data on the relation between $\mathrm{BP}$ and $\mathrm{BMI}$ are available in children and adolescents in developing countries [36]. In a school-based survey of a representative sample of youth aged 9, 13, and 16 years in Canada, body mass index was consistently associated with SBP and DBP in all age-gender groups [37]. The present study revealed that adolescents with high blood pressure were 3.5 times more likely to be overweight or obese as compared to adolescents with normal blood pressure. BMI was a significant predictor of high blood pressure among adolescents of the present study, even after adjustment for all potential predictors. This finding was in agreement with 
TABle 2: Prevalence of elevated blood pressure among study sample of school adolescents in relation to different types of obesity.

\begin{tabular}{|c|c|c|c|c|c|}
\hline \multirow{2}{*}{ Indicators of obesity } & \multicolumn{2}{|c|}{ Prevalence } & \multirow[t]{2}{*}{$\chi^{2 \mathrm{MH}}(P)$} & \multirow[t]{2}{*}{$\operatorname{cOR}(95 \% \mathrm{CI})$} & \multirow[t]{2}{*}{$\mathrm{aOR}(95 \% \mathrm{CI})^{\#}$} \\
\hline & No. & $\%$ & & & \\
\hline \multicolumn{6}{|l|}{ BMI percentiles } \\
\hline Overweight/obese $(519,34.6 \%)$ & 90 & 17.3 & $50.93(<.001)$ & $3.47(2.44-4.93)$ & $2.18(1.38-3.44)$ \\
\hline Nonoverweight/nonobese $(981,65.4 \%)$ & 56 & 5.7 & & $1^{@}$ & \\
\hline \multicolumn{6}{|l|}{ WHR } \\
\hline Obese $(241,16.1 \%)$ & 36 & 14.9 & $8.12(.004)$ & $1.83(1.22-2.75)$ & $1.27(0.82-1.96)$ \\
\hline Non obese $(1295,83.9 \%)$ & 110 & 8.7 & & $1^{@}$ & \\
\hline \multicolumn{6}{|l|}{ WC percentiles } \\
\hline Obese $(68,4.5 \%)$ & 27 & 39.7 & $67.52(<.001)$ & $4.27(2.97-6.15)$ & $3.14(1.67-5.94)$ \\
\hline Non obese $(1432,95.5 \%)$ & 119 & 8.3 & & $1^{\circledR}$ & \\
\hline \multicolumn{6}{|l|}{ WHtR } \\
\hline Obese $(250,16.7 \%)$ & 60 & 24.0 & $69.23(<.001)$ & $7.27(4.32-12.23)$ & $1.61(0.94-2.74)$ \\
\hline Non obese $(1250,83.3 \%)$ & 86 & 6.9 & & $1^{@}$ & \\
\hline
\end{tabular}

${ }^{\circledR}$ Reference category.

\#Adjustment was made for age, sex, smoking behaviour, food and salt consumption, history of chronic disease, family history of hypertension, diabetes mellitus, and obesity.

TABLE 3: Prevalence of elevated blood pressure among study sample of school adolescents in relation to medical and family history of chronic diseases/conditions and health behaviours.

\begin{tabular}{|c|c|c|c|c|}
\hline & \multicolumn{2}{|c|}{ Prevalence } & \multirow{2}{*}{$\chi^{2 \mathrm{MH}}(P)$} & \multirow{2}{*}{ OR (95\% CI) } \\
\hline & No. & $\%$ & & \\
\hline \multicolumn{5}{|c|}{ (a) Medical and family history } \\
\hline \multicolumn{5}{|l|}{ History of chronic disease } \\
\hline Positive $(102,6.8 \%)$ & 20 & 19.6 & $10.96(<.001)$ & $2.46(1.46-4.15)$ \\
\hline Negative $(1398,93.2 \%)$ & 126 & 9.0 & & $1^{\circledR}$ \\
\hline \multicolumn{5}{|l|}{ FH hypertension } \\
\hline Positive $(641,42.7 \%)$ & 78 & 12.2 & $7.07(.008)$ & $1.61(1.14-2.27)$ \\
\hline Negative $(859,57.3 \%)$ & 68 & 7.9 & & $1^{@}$ \\
\hline \multicolumn{5}{|l|}{ FH diabetes mellitus } \\
\hline Positive $(721,48.1 \%)$ & 84 & 11.7 & $5.39(.02)$ & $1.53(1.08-2.15)$ \\
\hline Negative $(779,51.9 \%)$ & 62 & 8.4 & & $1^{@}$ \\
\hline \multicolumn{5}{|l|}{ FH obesity } \\
\hline Positive $(571,38.1 \%)$ & 63 & 11.0 & $1.54(.21)$ & $1.26(0.89-1.79)$ \\
\hline Negative $(929,61.9 \%)$ & 83 & 8.9 & & $1^{@}$ \\
\hline \multicolumn{5}{|c|}{ (b) Health behaviors } \\
\hline \multicolumn{5}{|l|}{ Sport participation } \\
\hline Never $(415,27.7 \%)$ & 35 & 8.4 & $0.91(.34)$ & $0.81(0.54-1.21)$ \\
\hline Yes $(1085,72.3 \%)$ & 111 & 10.2 & & $1^{@}$ \\
\hline \multicolumn{5}{|l|}{ Smoking behavior } \\
\hline Smoker $(57,3.8 \%)$ & 9 & 15.8 & $1.81(.12)$ & $1.79(0.86-3.72)$ \\
\hline Nonsmoker $(443,96.2 \%)$ & 137 & 9.5 & & $1^{@}$ \\
\hline \multicolumn{5}{|l|}{ Salt consumption } \\
\hline Very high/high $(268,17.9 \%)$ & 28 & 10.4 & $0.10(.75)$ & $1.10(0.71-1.70)$ \\
\hline Moderate + little $(1232,82.1 \%)$ & 118 & 9.6 & & $1^{@}$ \\
\hline \multicolumn{5}{|l|}{ Fat consumption } \\
\hline Very high + high $(149,9.9 \%)$ & 11 & 7.4 & $0.76(.38)$ & $0.72(0.38-1.36)$ \\
\hline Moderate + little $(1351,90.1 \%)$ & 135 & 10.0 & & $1^{@}$ \\
\hline
\end{tabular}


a previous followup study of adolescents for 31.5 years, where a BMI above the 95th percentile in adolescence predicted adult mortality rates, and a $10-\mathrm{kg}$ higher body weight was associated with a $3.0-\mathrm{mmHg}$ higher systolic and a $2.3-\mathrm{mmHg}$ higher diastolic blood pressure. These increases translate into an estimated $12 \%$ increased risk for CHD and $24 \%$ increased risk for stroke [38].

WC was more powerful than BMI for predicting the incidence of hypertension in a previous study [39]. In obese adolescents, the accumulation of excess fat is known to occur predominantly in the upper body rather than in the peripheral region [40]. The increased waist circumference is unlikely to be due to visceral adipose tissue alone; it probably reflects both visceral and subcutaneous fat, and, hence, total fatness. In contrast, the body mass index measures the sum of fat mass and fat-free mass, and it is impossible to know the relative contributions of each. The present study showed that adolescents with high blood pressure were more than 7 times more likely to be obese with central obesity (WC percentiles $>90$ th for gender and age) as compared to those with normal blood pressure. In a study of British youth aged 11-16 years, waist circumference, representing central fatness, has increased much faster than body mass index over 10-20 years [40].

It has been reported in a previous study that combination of BMI and WC is more strongly related to CVD risk factors than BMI or WC alone [41]. In the present study, after adjustment for all other body composition measures, both WC and BMI were the only significant predictors of high blood pressure in adolescents. Few studies have shown that waist circumference may be a better predictor of cardiovascular disease than BMI $[42,43]$ and waist-to-hip ratio [43].

Adjustments of WC by stature (WHtR) or hip circumference (WHR) were found to improve its association with the incidence of hypertension [39]. WHtR was recommended, being more highly correlated with visceral fat mass and clustering of cardiovascular risk factors in children and adults [24]. It may be a more accurate tracking indicator of fat distribution and accumulation by age, because it accounts for the growth in both WC and height over age, particularly in children and adolescents [24]. In the present study, adolescents with high blood pressure were 2 times and 7 times to be obese according to the WHR and WHtR, respectively. However, after adjustment with all other body composition measures, this association was not significant. This finding is in accordance with what was reported in a previous study that the use of ratios such as WHR to assess obesity in children and adolescents may not be appropriate because they are highly age dependent and may obscure stronger relations that may be present with separate circumference measurements. Furthermore, differences in skeletal structure may confound the results [44].

This study has some limitations which should be considered when interpreting these findings. First, BP was measured on one single visit whereas hypertension should be based on readings taken on several visits [45]. However, most other epidemiological studies of BP in children also relied on single-visit readings [46-49]. Second, we relied upon the
US reference BP values. However, these US reference data have the advantage of being adjusted for sex, age, and height, which are the main known physiological determinants of BP in children [45]. This might affect the estimates of elevated $\mathrm{BP}$, yet it is unlikely to have biased our findings on the relationship between BP and body composition measures. Third, the study relied upon a written questionnaire for information on lifestyles and health behaviours, such as exercising, food and salt consumption, and smoking behaviour. If the accuracy of self-reported lifestyles differed by obesity, then our effect estimate might have been biased. Fourth, we cannot be certain of the causal direction of the associations observed between obesity and high blood pressure, due to the study's cross-sectional design. A longitudinal study with repeated measures of body composition and blood pressure would be desirable in the future.

In conclusion, this study provides important evidence of the association between both overall obesity, based on BMI percentiles and central obesity, based on WC percentiles and high blood pressure among Egyptian adolescents.

From this work, the following recommendations could be suggested.

(1) Hypertension screening should be included in a school health program. Followup and regular blood pressure measurement should be an important step in school health programs. Waist circumference should be measured in the school clinic. It could be used in a health promotion program to identify individuals who should seek, and be offered, weight management and those at risk of developing hypertension.

(2) Prevention of cardiovascular risk factors as early as childhood may be an important strategy to prevent noncommunicable diseases in a life course perspective, particularly in settings with scarce resources and limited health care capacity. Programs and policies to limit sedentary behaviours and promote physical activity and healthy nutrition among children are recommended.

\section{References}

[1] M. B. Lande, N. L. Carson, J. Roy, and C. C. Meagher, "Effects of childhood primary hypertension on carotid intima media thickness: a matched controlled study," Hypertension, vol. 48, no. 1, pp. 40-44, 2006.

[2] A. Must, P. F. Jacques, G. E. Dallal, C. J. Bajema, and W. H. Dietz, "Long-term morbidity and mortality of overweight adolescents - a follow-up of the Harvard Growth Study of 1922 to 1935," The New England Journal of Medicine, vol. 327, no. 19, pp. 1350-1355, 1992.

[3] D. R. Labarthe, "Prevention of cardiovascular risk factors in the first place," Preventive Medicine, vol. 29, no. 6, pp. S72S78, 1999.

[4] J. M. Sorof, D. Lai, J. Turner, T. Poffenbarger, and R. J. Portman, "Overweight, ethnicity, and the prevalence of hypertension in school-aged children," Pediatrics, vol. 113, no. 3, pp. 475-482, 2004. 
[5] G. Paradis, M. Lambert, J. O'Loughlin et al., "Blood pressure and adiposity in children and adolescents," Circulation, vol. 110, no. 13, pp. 1832-1838, 2004.

[6] S. Genovesi, M. Giussani, F. Pieruzzi et al., "Results of blood pressure screening in a population of school-aged children in the province of Milan: role of overweight," Journal of Hypertension, vol. 23, no. 3, pp. 493-497, 2005.

[7] E. A. Saleh, A. A. Mahfouz, K. Y. Tayel, M. K. Naguib, and N. M. Bin-AL-Shaikh, "Study of blood pressure levels among Kuwaiti primary school children," Eastern Mediterranean Health Journal, vol. 6, pp. 333-337, 2000.

[8] H. Y. Jaddou, A. M. Bateiha, A. M. Khawaldeh, Y. M. Goussous, and K. M. Ajlouni, "Blood pressure profile in schoolchildren and adolescents in Jordan," Annals of Saudi Medicine, vol. 21, no. 1-2, pp. 123-126, 2001.

[9] O. Darwish, A. El Ghamry, M. Hussein, and S. Omara, "Prevalence and some etiological factors of hypertension in school children," Bulletin High Institute of Public Health, vol. 15, no. 3, pp. 97-110, 1985.

[10] P. Bundred, D. Kitchiner, and I. Buchan, "Prevalence of overweight and obese children between 1989 and 1998: population based series of cross sectional studies," The British Medical Journal, vol. 322, no. 7282, pp. 326-328, 2001.

[11] J. O’loughlin, G. Paradis, G. Meshefedjian, and K. GrayDonald, "A five-year trend of increasing obesity among elementary schoolchildren in multiethnic, low-income, innercity neighborhoods in Montreal, Canada," International Journal of Obesity, vol. 24, no. 9, pp. 1176-1182, 2000.

[12] Q. He, Z. Y. Ding, D. Y. T. Fong, and J. Karlberg, "Blood pressure is associated with body mass index in both normal and obese children," Hypertension, vol. 36, no. 2, pp. 165-170, 2000.

[13] F. Z. Tan, H. M. Dong, G. H. Feng et al., "Study on the relations between overweight, obesity, blood pressures, serum lipids and glucose in schoolchildren of Shijiazhunag," Zhonghua Liu Xing Bing Xue Za Zhi, vol. 26, no. 8, pp. 592-595, 2005.

[14] P. Muntner, J. He, J. A. Cutler, R. P. Wildman, and P. K. Whelton, "Trends in Blood Pressure among Children and Adolescents," Journal of the American Medical Association, vol. 291, no. 17, pp. 2107-2113, 2004.

[15] J. Ribeiro, S. Guerra, A. Pinto, J. Oliveira, J. Duarte, and J. Mota, "Overweight and obesity in children and adolescents: relationship with blood pressure, and physical activity," Annals of Human Biology, vol. 30, no. 2, pp. 203-213, 2003.

[16] J. M. Sorof, D. Lai, J. Turner, T. Poffenbarger, and R. J. Portman, "Overweight, ethnicity, and the prevalence of hypertension in school-aged children," Pediatrics, vol. 113, no. 3, pp. 475-482, 2004.

[17] C. B. Ebbeling, D. B. Pawlak, and D. S. Ludwig, "Childhood obesity: public-health crisis, common sense cure," The Lancet, vol. 360, no. 9331, pp. 473-482, 2002.

[18] T. H. Jafar, M. Islam, N. Poulter et al., "Children in South Asia have higher body mass-adjusted blood pressure levels than white children in the United States: a comparative study," Circulation, vol. 111, no. 10, pp. 1291-1297, 2005.

[19] C. Agyemang, W. K. Redekop, E. Owusu-Dabo, and M. A. Bruijnzeels, "Blood pressure patterns in rural, semi-urban and urban children in the Ashanti region of Ghana, West Africa," BMC Public Health, vol. 5, article 114, 2005.

[20] K. D. Monyeki, H. C. G. Kemper, and P. J. Makgae, "The association of fat patterning with blood pressure in rural South African children: the Ellisras Longitudinal Growth and Health Study," International Journal of Epidemiology, vol. 35, no. 1, pp. 114-120, 2006.
[21] L. Ke, K. E. Brock, R. V. Cant, Y. Li, and S. L. Morrell, "The relationship between obesity and blood pressure differs by ethnicity in Sydney school children," American Journal of Hypertension, vol. 22, no. 1, pp. 52-58, 2009.

[22] Q. He, Z. Y. Ding, D. Y. T. Fong, and J. Karlberg, "Blood pressure is associated with body mass index in both normal and obese children," Hypertension, vol. 36, no. 2, pp. 165-170, 2000.

[23] R. Y. T. Sung, C. C. W. Yu, K. C. Choi et al., "Waist circumference and body mass index in Chinese children: cutoff values for predicting cardiovascular risk factors," International Journal of Obesity, vol. 31, no. 3, pp. 550-558, 2007.

[24] C. Li, E. S. Ford, A. H. Mokdad, and S. Cook, "Recent trends in waist circumference and waist-height ratio among US children and adolescents," Pediatrics, vol. 118, no. 5, pp. e1390-e1398, 2006.

[25] M. E. Lean, T. S. Han, and C. E. Morrison, "Waist circumference as a measure for indicating need for weight management," The British Medical Journal, vol. 311, no. 6998, pp. 158-161, 1995.

[26] Centers for Disease Control and Prevention. Growth charts. Available at: http://www.cdc.gov/growthcharts/, November, 2010.

[27] M. I. Goran, G. D. C. Ball, and M. L. Cruz, "Cardiovascular endocrinology 2: obesity and risk of type 2 diabetes and cardiovascular disease in children and adolescents," Journal of Clinical Endocrinology and Metabolism, vol. 88, no. 4, pp. 1417-1427, 2003.

[28] Centers for Disease Control and Prevention, The Third National Health and Nutrition Examination Survey (NHANES III 1988-1994) Reference Manuals and Reports [CD-ROM], National Center for Health Statistics, Bethesda, Md, USA, 2005.

[29] WHO, Measuring Obesity: Classification and Description of Anthropometric Data, WHO, Copenhagen, Germany, 1989.

[30] B. Falkner and S. R. Daniels, "Summary of the fourth report on the diagnosis, evaluation, and treatment of high blood pressure in children and adolescents," Hypertension, vol. 44, no. 4, pp. 387-388, 2004.

[31] A. V. Chobanian, G. L. Bakris, H. R. Black et al., "The Seventh report of the Joint National Committee on Prevention, Detection, Evaluation, and Treatment of High Blood Pressure: the JNC 7 Report," Journal of the American Medical Association, vol. 289, no. 19, pp. 2560-2572, 2003.

[32] M. A. Abolfotouh, F. A. Bassiouni, G. M. Mounir, and R. C. Fayyad, "Health-related lifestyles and risk behaviours among students living in Alexandria University hostels," Eastern Mediterranean Health Journal, vol. 13, no. 2, pp. 376-391, 2007.

[33] M. Rafraf, B. P. Gargari, and A. Safaiyan, "Prevalence of prehypertension and hypertension among adolescent high school girls in Tabriz, Iran," Food and Nutrition Bulletin, vol. 31, no. 3, pp. 461-465, 2010.

[34] K. L. McNiece, T. S. Poffenbarger, J. L. Turner, K. D. Franco, J. M. Sorof, and R. J. Portman, "Prevalence of hypertension and pre-hypertension among adolescents," Journal of Pediatrics, vol. 150, no. 6, pp. 640-644, 2007.

[35] K. D. Monyeki, H. C. G. Kemper, and P. J. Makgae, "The association of fat patterning with blood pressure in rural South African children: the Ellisras Longitudinal Growth and Health Study," International Journal of Epidemiology, vol. 35, no. 1, pp. 114-120, 2006.

[36] A. Chiolero, G. Madeleine, A. Gabriel, M. Burnier, F. Paccaud, and P. Bovet, "Prevalence of elevated blood pressure and 
association with overweight in children of a rapidly developing country," Journal of Human Hypertension, vol. 21, no. 2, pp. 120-127, 2007.

[37] G. Paradis, M. Lambert, J. O’Loughlin et al., "Blood pressure and adiposity in children and adolescents," Circulation, vol. 110, no. 13, pp. 1832-1838, 2004.

[38] P. Poirier, T. D. Giles, G. A. Bray et al., "Obesity and cardiovascular disease: pathophysiology, evaluation, and effect of weight loss," Circulation, vol. 113, no. 6, pp. 898-918, 2006.

[39] F. D. Fuchs, M. Gus, L. B. Moreira et al., "Anthropometrie indices and the incidence of hypertension: a comparative analysis," Obesity Research, vol. 13, no. 9, pp. 1515-1517, 2005.

[40] H. D. McCarthy, S. M. Ellis, and T. J. Cole, "Central overweight and obesity in British youth aged 11-16 years: cross sectional surveys of waist circumference," The British Medical Journal, vol. 326, no. 7390, pp. 624-626, 2003.

[41] S. Zhu, S. Heshka, Z. Wang et al., "Combination of BMI and waist circumference for identifying cardiovascular risk factors in whites," Obesity Research, vol. 12, no. 4, pp. 633-645, 2004.

[42] I. Janssen, P. T. Katzmarzyk, and R. Ross, "Waist circumference and not body mass index explains obesity-related health risk," American Journal of Clinical Nutrition, vol. 79, no. 3, pp. 379384, 2004.

[43] C. Maffeis, A. Pietrobelli, A. Grezzani, S. Provera, and L. Tatò, "Waist circumference and cardiovascular risk factors in prepubertal children," Obesity Research, vol. 9, no. 3, pp. 179187, 2001.

[44] R. W. Taylor, I. E. Jones, S. M. Williams, and A. Goulding, "Evaluation of waist circumference, waist-to-hip ratio, and the conicity index as screening tools for high trunk fat mass, as measured by dual-energy X-ray absorptiometry, in children aged 3-19 y," American Journal of Clinical Nutrition, vol. 72, no. 2, pp. 490-495, 2000.

[45] B. Falkner, S. R. Daniels, J. T. Flynn et al., "The fourth report on the diagnosis, evaluation, and treatment of high blood pressure in children and adolescents," Pediatrics, vol. 114, no. 2, supplement, pp. 555-576, 2004.

[46] G. Paradis, M. Lambert, J. O’Loughlin et al., "Blood pressure and adiposity in children and adolescents," Circulation, vol. 110, no. 13, pp. 1832-1838, 2004.

[47] T. H. Jafar, M. Islam, N. Poulter et al., "Children in South Asia have higher body mass-adjusted blood pressure levels than white children in the United States: a comparative study," Circulation, vol. 111, no. 10, pp. 1291-1297, 2005.

[48] S. Greenland and K. Drescher, "Maximum likelihood estimation of the attributable fraction from logistic models," Biometrics, vol. 49, no. 3, pp. 865-872, 1993.

[49] B. Falkner, S. S. Gidding, G. Ramirez-Garnica, S. A. Wiltrout, D. West, and E. B. Rappaport, "The relationship of body mass index and blood pressure in primary care pediatric patients," Journal of Pediatrics, vol. 148, no. 2, pp. 195-200, 2006. 


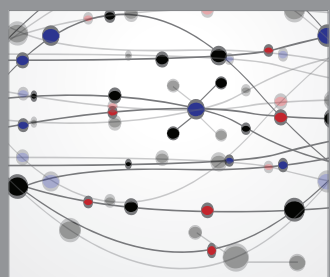

The Scientific World Journal
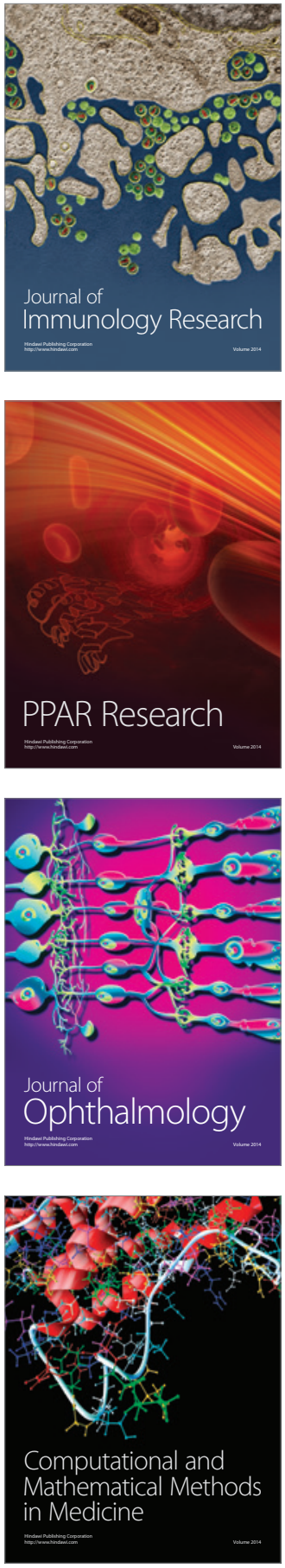

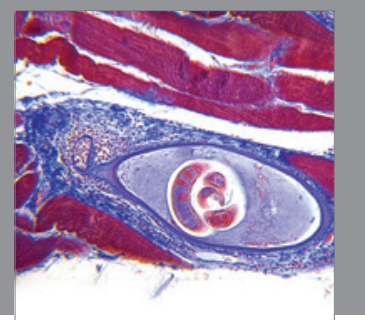

Gastroenterology

Research and Practice
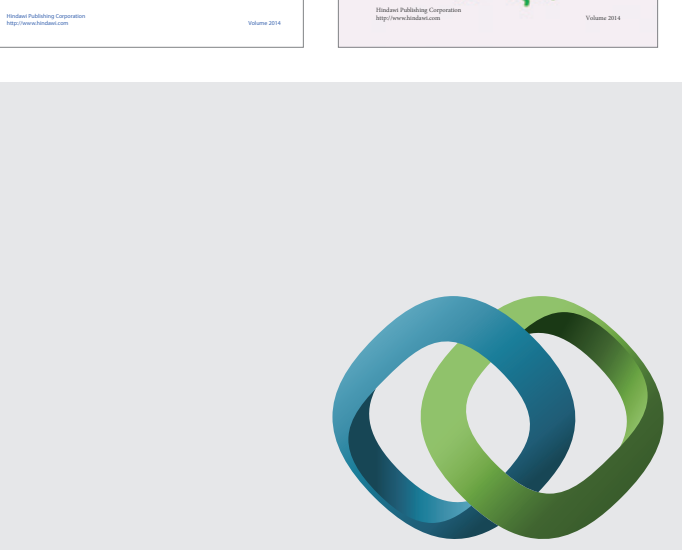

\section{Hindawi}

Submit your manuscripts at

http://www.hindawi.com
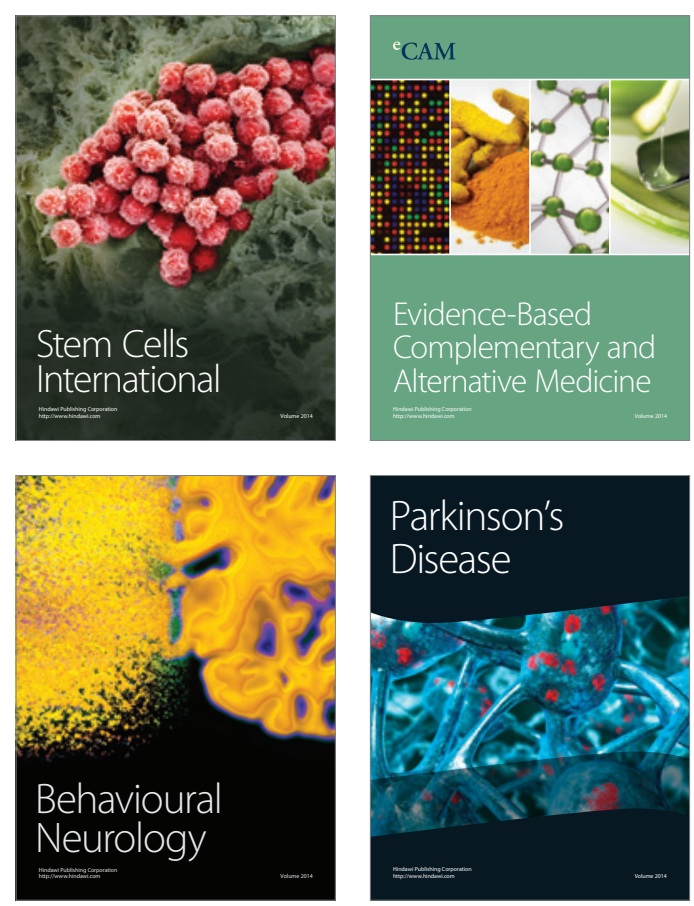

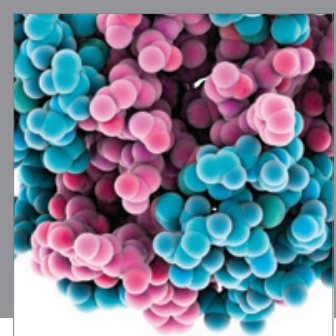

Journal of
Diabetes Research

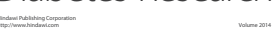

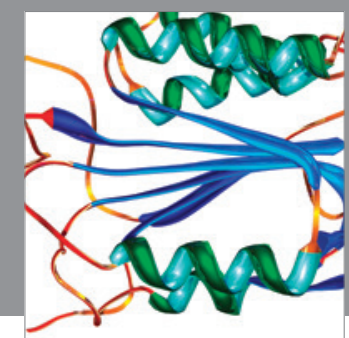

Disease Markers
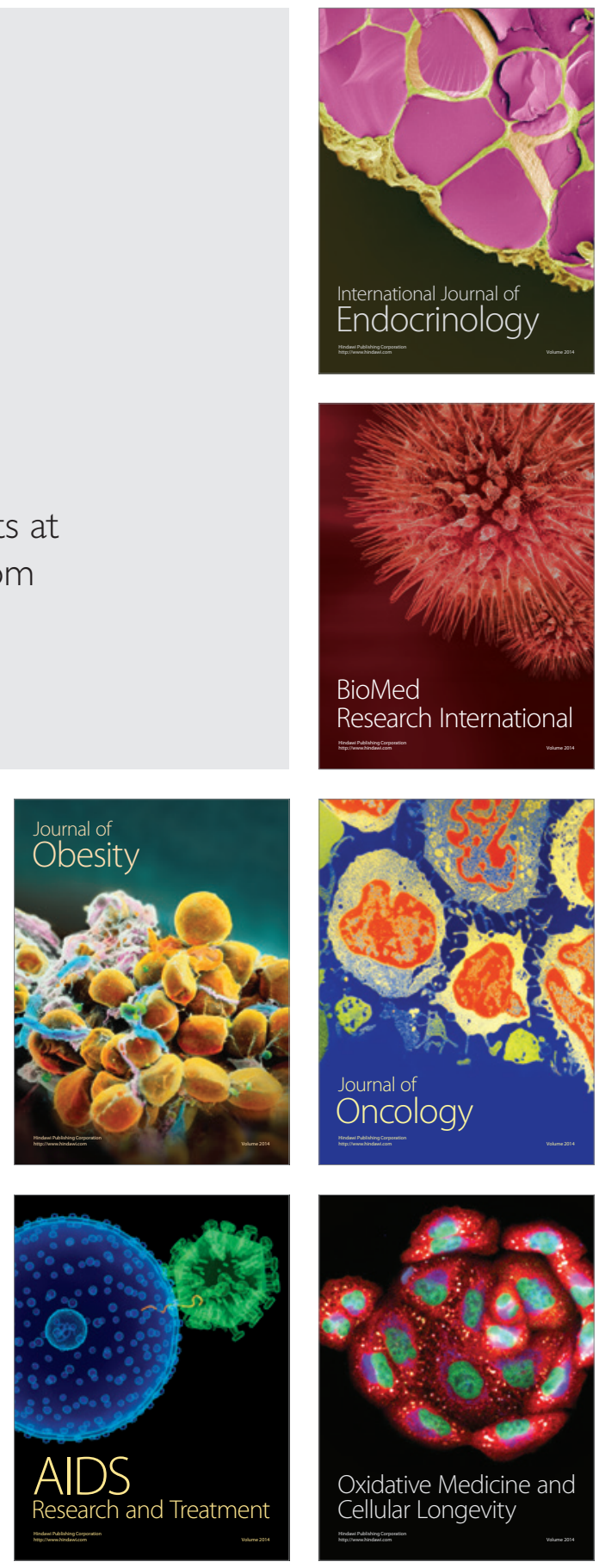